\title{
Electrodeposition Behaviors of Zn-Ni Alloy on Copper Foil with Carrier
}

\author{
Gengfeng Deng ${ }^{1,2, a^{*}}$, Qinghua Zeng ${ }^{1,2, b}$, Jueqi Huang ${ }^{1, c}$ \\ ${ }^{1}$ School of Metallurgical and Chemical Engineering, Jiangxi University of Science and Technology, \\ Ganzhou, Jiangxi 341000, P R China \\ ${ }^{2}$ School of Computing, Engineering and Mathematics, University of Western Sydney, Penrith NSW \\ 2751, Australia \\ agfdeng26@126.com, bq.zeng@uws.edu.au, ${ }^{c} 569493482 @ q q . c o m$
}

\begin{abstract}
Keywords: Electrodeposition, Zn-Ni Alloy, Ultra-thin copper foil, Peeling layer, copper carrier Abstract: Zn-Ni alloy is a promising peeling layer of ultra-thin copper foil with carrier support due to its good binding properties with copper matrix. We present here our recent work on the electrodeposition behaviors of $\mathrm{Zn}-\mathrm{Ni}$ alloy peeling layer on ultra-thin copper foil with carrier support by cyclic voltammetry and chronoamperometry. The results show that in pyrophosphate solution the deposition of Zn-Ni alloy on copper foil is a normal co-deposition , the deposition processes start with the deposition of nickel on carrier copper foil, followed by the co-deposition of zinc-nickel upon the reach of zinc deposition potential. Moreover, such deposition is a quasi-reversible process controlled by diffusion and the nucleation of $\mathrm{Zn}-\mathrm{Ni}$ alloy follows a three-dimensional instantaneous nucleation model.
\end{abstract}

\section{Introduction}

$\mathrm{Zn}-\mathrm{Ni}$ alloy has drawn significant attentiondue to its high corrosion resistance, good binding with the substrate, excellent processability, high weldability, and low cost. Such Zn-Ni alloy has been widely used in aviation, aerospace, light industry, and household appliances [1-3].

In particular, Zn-Ni alloy has been regarded as a promising peeling layer of copper foil. Yet, to fully explore such alloy in copper foil, it is of importance to understand its deposition mechanisms. In the past years, some efforts have been made to understand the deposition mechanisms but led to contradictory conclusions. According to thermodynamics, nickel would deposit on copper substrate more easily and quickly than zinc since nickel and zinc have standard electrode potentials $-0.76 \mathrm{~V}$ and $-0.25 \mathrm{~V}$, respectively. Niu reported that the deposition of zinc-nickel alloy in alkaline solution is a normal co-deposition [4]. However, Brenner believed that it is a typical abnormal co-deposition in which zinc deposits first, followed by the deposition of nickel [5]. On the basis of a series of polarization curves of $\mathrm{Zn}-\mathrm{Ni}$ alloy in alkaline plating system, Kong found that $\mathrm{Zn}-\mathrm{Ni}$ alloy follows normal co-deposition at lower current density and abnormal co-deposition at higher current density [6]. Despite of a large number of studies on the deposition mechanisms of $\mathrm{Zn}-\mathrm{Ni}$ alloy's [7-10], it is still unclear how the different factors and system conditions affect the electrodeposition of Zn-Ni alloy.

The present work is to make use of the good binding properties between $\mathrm{Zn}-\mathrm{Ni}$ alloy and the matrix and to improve the peeling properties of ultra-thin copper foil with carrier support using Zn-Ni alloy as a peeling layer [11]. Specifically, electrochemical method will be employed to measure the curves of cyclic voltammetry and chronoamperometry of zinc-nickel alloy deposited on copper foil with carrier support. The electrodeposition mechanisms and deposition model of $\mathrm{Zn}-\mathrm{Ni}$ alloy on copper foil are analyzed, which would provide some theoretical basis to achieve an ultra-thin copper foil with a stable peeling strength, and further expand the applications of $\mathrm{Zn}-\mathrm{Ni}$ alloy. 


\section{Experiments}

Electrochemical test was carried out on AUTOLAB P301 (Netherlands, Autolab Scientific Instrument Co. Ltd.) in which saturated electrode calomel (SEC) was used as a reference electrode, platinum electrode as counter electrode, and carrier copper foil as working electrode. Prior to the test, the electrode surface was treated by dilute sulfuric acid and deionized water. Then, the electrodes were soaked for 15 mins in the open-circuit voltage. The main components of the plating bath of zinc-nickel alloy layer were as follows: $\mathrm{ZnSO}_{4} \cdot 7 \mathrm{H}_{2} \mathrm{O} 0.15 \mathrm{~mol} \cdot \mathrm{L}^{-1}$, $\mathrm{NiSO}_{4} \cdot 6 \mathrm{H}_{2} \mathrm{O} 0.05 \mathrm{~mol} \cdot \mathrm{L}^{-1}$ and $\mathrm{K}_{4} \mathrm{P}_{2} \mathrm{O}_{7} \cdot 3 \mathrm{H}_{2} \mathrm{O}$ $0.5 \mathrm{~mol} \cdot \mathrm{L}^{-1}$. Finally, the obtained data were handled by the softwares of AUTOLAB electrochemical workstation and Origin7.0.

\section{Results and Discussions}

Cyclic voltammetry curves of zinc-nickel alloy layer. To understand the deposition of $\mathrm{Zn}-\mathrm{Ni}$ alloy on copper foil, the cyclic voltammetry curves of deposited $\mathrm{Zn}, \mathrm{Ni}$, and $\mathrm{Zn}-\mathrm{Ni}$ alloy in the potassium pyrophosphate system have been studies respectively. As shown in Fig.1a, there is a pair of redox peaks in its cyclic voltammetry curve when the electrical potential is changed from $0 \mathrm{~V}$ to $-1.4 \mathrm{~V}$ and then back to $0 \mathrm{~V}$. Moreover, both peaks are not in very good symmetry. The reduction peak of zinc ion appears at $-0.81 \mathrm{~V}$, which indicates the electrodeposition of zinc occurs at this electrical potential. For the case of nickel, the cyclic voltammetry curve (Fig. 1b) shows a reduction peak at $-0.29 \mathrm{~V}$. Fig. 1c shows the cyclic voltammetry curve of zinc-nickel alloy, which has two oxidation peaks (A and B) and two reduction peaks (C and D). Compared with Fig. 1a and $1 \mathrm{~b}$, peak $\mathrm{C}$ should be the reduction of nickel ion in the alloy liquid. Its reduction potential has been reduced from $-0.29 \mathrm{~V}$ of single nickel deposition to $-0.61 \mathrm{~V}$. Meanwhile, peak $\mathrm{D}$ is the reduction of zinc ion and its reduction potential has been increased from $-0.81 \mathrm{~V}$ of single zinc deposition to $-0.72 \mathrm{~V}$. Thus, in $\mathrm{Zn}-\mathrm{Ni}$ alloy liquid, the deposition potentials of zinc and nickel become very closer, which indicates that nickel and zinc are very easy to co-deposit in a normal way in the potassium pyrophosphate system. Therefore, in the present $\mathrm{Zn}-\mathrm{Ni}$ alloy system, nickel deposits first on the carrier copper foil, followed by the co-deposition of zinc-nickel when the potential reaches the electrical potential of zinc's deposition.

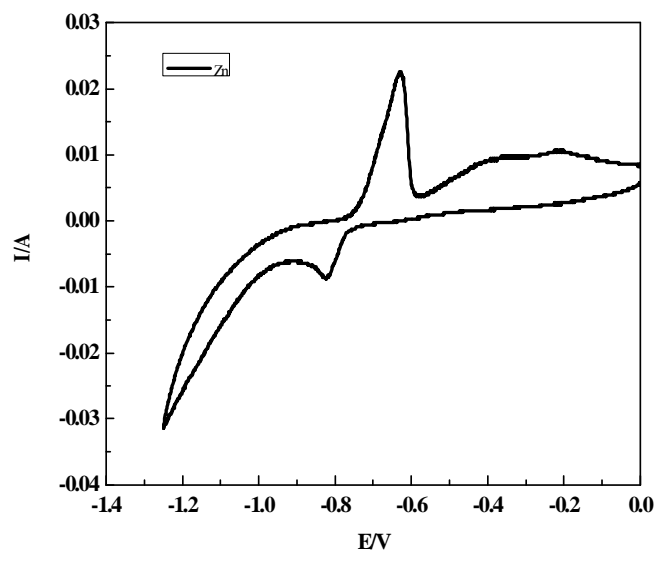

(a) $\mathrm{Zn}\left(0.15 \mathrm{~mol} \cdot \mathrm{L}^{-1} \mathrm{ZnSO}_{4} \cdot 7 \mathrm{H}_{2} \mathrm{O}\right)$

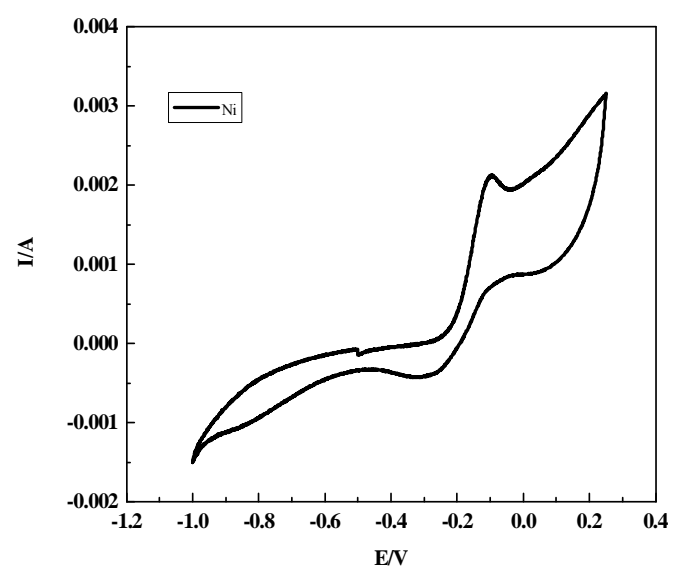

(b) $\mathrm{Ni}\left(0.05 \mathrm{~mol} \cdot \mathrm{L}^{-1} \mathrm{NiSO}_{4} \cdot 6 \mathrm{H}_{2} \mathrm{O}\right)$ 


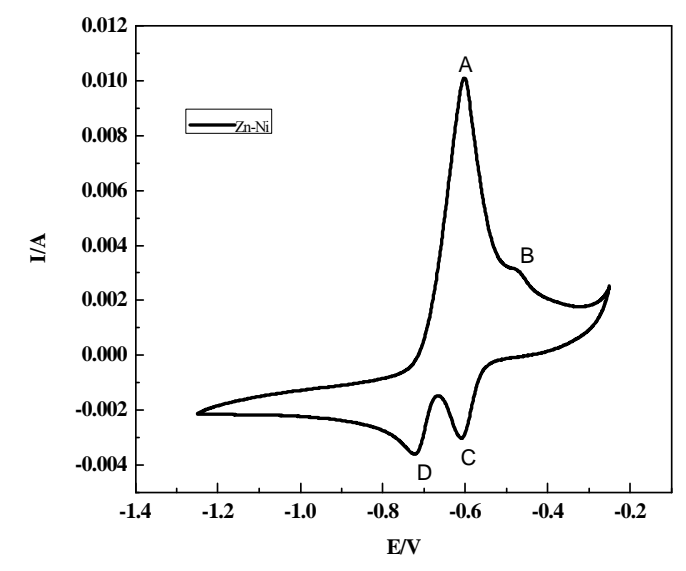

(c) $\mathrm{Zn}-\mathrm{Ni}\left(0.15 \mathrm{~mol} \cdot \mathrm{L}^{-1} \mathrm{ZnSO}_{4} \cdot 7 \mathrm{H}_{2} \mathrm{O}\right.$ and $\left.0.05 \mathrm{~mol} \cdot \mathrm{L}^{-1} \mathrm{NiSO}_{4} \cdot 6 \mathrm{H}_{2} \mathrm{O}\right)$

Fig. 1 Cyclic voltammetry curves of the deposition of $\mathrm{Zn}, \mathrm{Ni}$, and $\mathrm{Zn}-\mathrm{Ni}$ in potassium pyrophosphate system.

Control process of the formation of zinc-nickel alloy layer. In an electrode reaction, if the reaction is reversible, its peak voltage $E_{p}$ does not depend on the scanning speed. However, if it is irreversible, there is no electrical current when it scans reversely. Fig. 2 shows the cyclic voltammetry curves of $\mathrm{Zn}-\mathrm{Ni}$ alloys co-deposition at different scanning speed in pyrophosphate system.

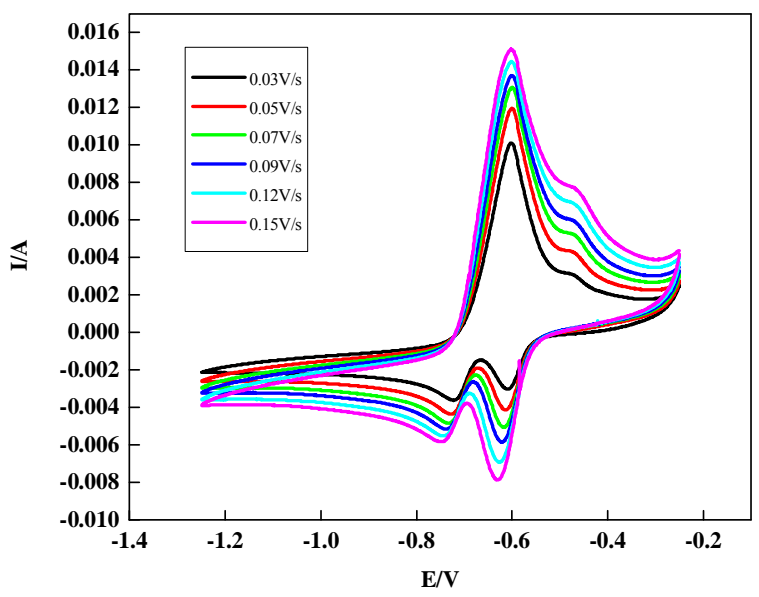

Fig. 2 The cyclic voltammetry curves of Zn-Ni alloys co-deposition at different scanning speed.

There are two reduction peaks of $\mathrm{Zn}^{2+}$ and $\mathrm{Ni}^{2+}$ at about $-0.72 \mathrm{~V}$ and $-0.61 \mathrm{~V}$ respectively at different scanning speed when the potential scans from $0 \mathrm{~V}$ to $-1.4 \mathrm{~V}$. Also, there are two corresponding oxidation peaks of $\mathrm{Zn}$ and $\mathrm{Ni}$ when the electrical potential scans inverting, respectively. The difference of potential peaks of the oxidation and reduction is more than $0.1 \mathrm{~V}$ and increases with scanning speed, which indicates that the electrode reaction is irreversible to some degree. However, there is an electrical current during reverse scanning, which indicates no irreversible process. Thus the electrodeposition of $\mathrm{Zn}-\mathrm{Ni}$ alloy could be regarded as a quasi-reversible process.

According to the metal alloy electrodeposition theory proposed by Schwartz M. [12], if a quasi-reversible electrodeposition reaction is controlled by diffusion process, its peak reduction current $I_{p}$ on the cyclic voltammetry curve has a linear relationship with the square root of scanning speed $v$, given by Eq. 1.

$$
I_{p}=0.4058 n^{3 / 2} A c_{0}^{*} D_{0}^{1 / 2} v^{1 / 2}(\alpha F / R T)^{1 / 2}
$$


where $I_{p}$ - peak electrical current, A; $v-\operatorname{scan}$ speed, $\mathrm{V} \cdot \mathrm{s}^{-1} ; n-$ the number of electron transfer; $\mathrm{A}$ - the area of the electrode, $\mathrm{m}^{2} ; c_{0}^{*}$ — bulk solution concentration, mol $\cdot \mathrm{L}^{-1} ; D_{0}$ - diffusion coefficient, $\mathrm{m} \bullet \mathrm{s}^{-1} ; \alpha$ - cathode transfer coefficient; $F-$ Faraday constant; $R$ - gas constant, $\mathrm{J} \bullet(\mathrm{mol} \bullet \mathrm{K})^{-1} ; T$ - Temperature, $\mathrm{K}$.

Fig. 3 and 4 shows the dependence of peak reduction current $I_{p}$ on the square root of scanning speed $v$ for zinc and nickel respectively, which indicates an approximately linear relationship. Therefore, the co-deposition process of zinc-nickel alloy can be regarded as a quasi-reversible process controlled by diffusion in the potassium pyrophosphate system.

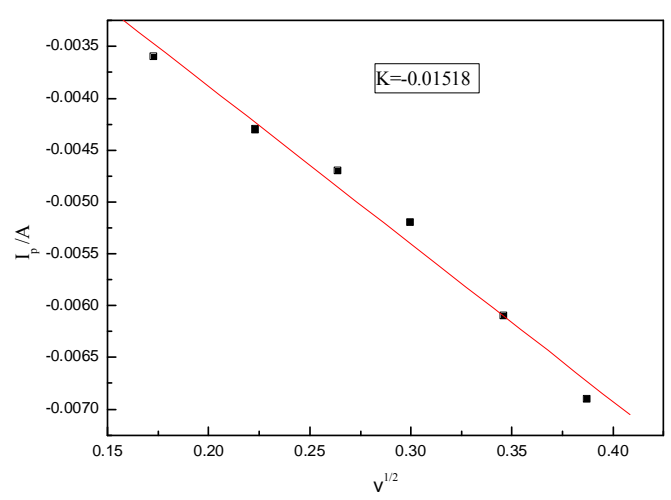

Fig. 3 The dependence of peak electrical current $\left(\mathrm{I}_{\mathrm{p}}\right)$ of zinc on the square root of scanning speed $\left(\mathrm{v}^{1 / 2}\right)$.

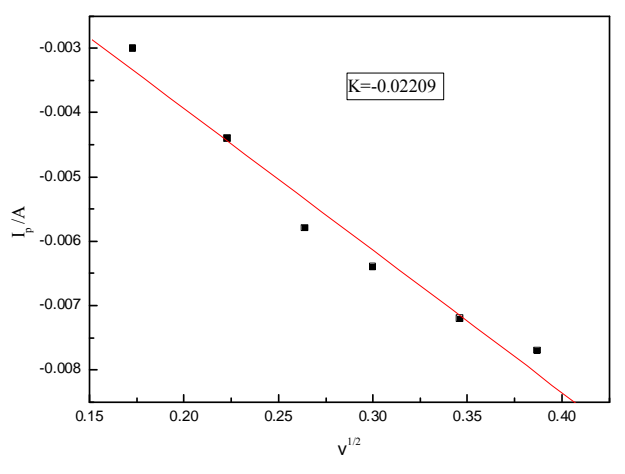

Fig. 4 The dependence of peak electrical current $\left(\mathrm{I}_{\mathrm{p}}\right)$ of nickel on the square root of scanning speed $\left(v^{1 / 2}\right)$.

Nucleation mechanism of electrodeposited zinc-nickel alloy. Metal electrodeposition involves in an interface of solution and electrode. The initial nucleation and growth generally include five stages, e.g., induction period, formation of critical crystal nucleus upon atomic adsorption, nucleus growth, overlapping of nucleus, and continuing growth of deposits. However, for a specific electrodeposition system, it is of great practical significance in studying and identifying the nucleation mechanism and deposition process model.

Chronoamperometry is a major method to study the nucleation mechanism of alloy electrodeposition and is used in the present experiments. Fig. 5 shows the chronoamperometry curve of zinc-nickel alloy deposited on copper foil electrode in potassium pyrophosphate system.

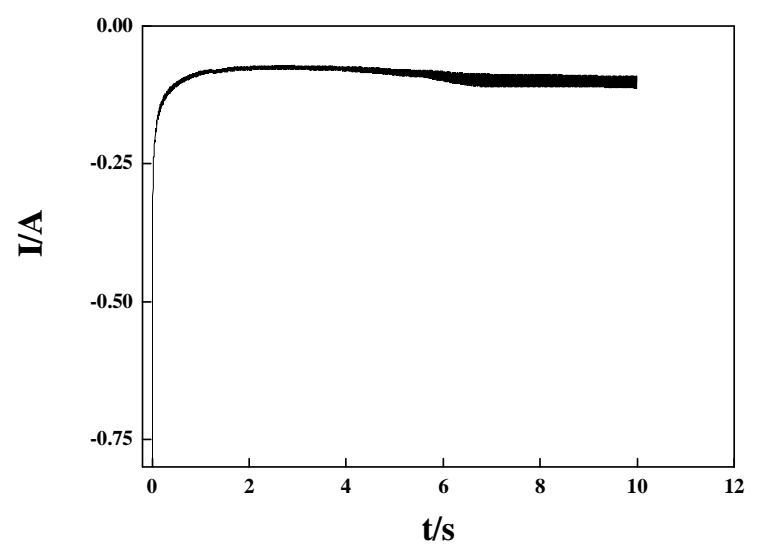

Fig. 5 Chronoamperometry curve of zinc-nickel deposited on copper foil in potassium pyrophosphate system. 
It is observed (Fig.5) that transient electrical current has an extreme value during the co-deposition of zinc-nickel alloy on copper foil. Moreover, the transient electrical current does not fall to zero with time on but tends to be a constant value. This result indicates a three-dimensional nucleation process for the present system. According to the diffusion-controlled nucleation and growth for hemispherical nuclei, there is no new nucleus to be formed during the growth of each nucleus [13]. Considering the overlapping between nuclei, two nucleation models are proposed for the three-dimensional electrodeposition process: instantaneous nucleation and continuous nucleation. The difference between both models is reflected from the relationship of electrical current $I$ and deposition time $t$ on their chronoamperometry curves, given by the following equations( Eq. 2, Eq. 3), respectively.

$$
\begin{gathered}
I(t)=\frac{z F N_{0} \pi(2 D C)^{3 / 2} M^{1 / 2}}{\rho^{1 / 2}} t^{1 / 2} \quad \text { (Instantaneous nucleation) } \\
I(t)=\frac{2 z F K_{n} N_{0} \pi(2 D C)^{3 / 2} M^{1 / 2}}{3 \rho^{1 / 2}} t^{3 / 2} \quad \text { (Continuous nucleation) }
\end{gathered}
$$

where, $N_{0}$ - the initial number of nucleation, $z-$ atomic valence, $M$ - the atomic weight of deposit, $\mathrm{g} \cdot \mathrm{mol}^{-1}, D$ - diffusion coefficient of deposition ions, $\mathrm{cm}^{2} \cdot \mathrm{s}^{-1}, C$ - volume concentration of deposition ions, $\mathrm{mol} \bullet \mathrm{cm}^{-3}, \rho$ - density of deposited metal or alloy, $\mathrm{g} \cdot \mathrm{cm}^{-3}, I(t)$ - the polarization electrical current at time $t, t$ - the polarize time, $K_{n}$ - nucleation constant

In Fig.5, the stage in which electrical current increases rapidly to a maximum is attributed to the nucleation process of the system while the stage in which electrical current starts to be flat from the maximum can be attributed to nucleus growth process.

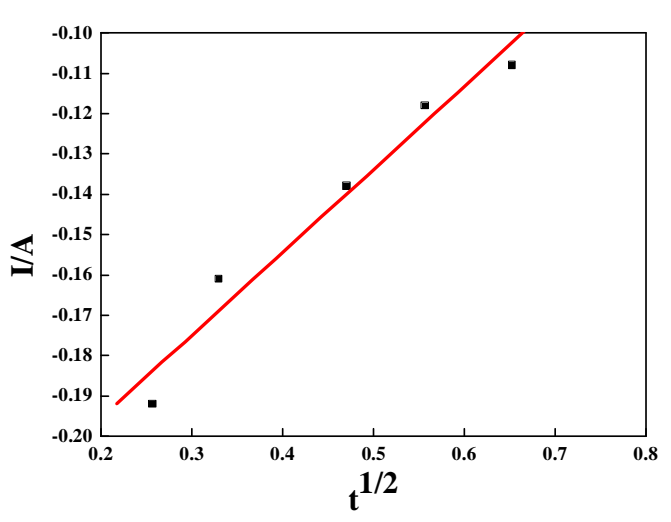

Fig. 6 The relationship of $I(t)$ with $t^{1 / 2}$ in the nucleation stage

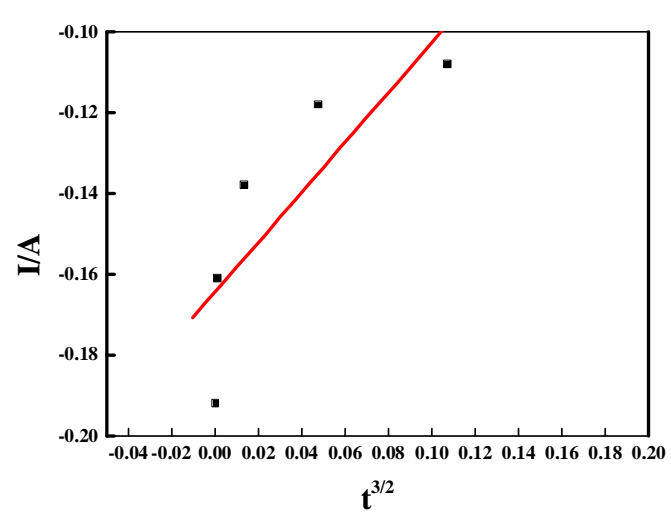

Fig. 7 The relationship of $I(t)$ with $t^{3 / 2}$ in the nucleation stage

Fig. 6 and 7 show the relationship between electrical current and deposition time. There is a rapid increase in electrical current with time during the nucleation stage. Moreover, the electrical current data $I$ has a linear relationship with the square root of deposition time $t^{1 / 2}$ but not with $t^{3 / 2}$. This could further confirm that the electrodeposition process of zinc-nickel alloy in potassium pyrophosphate system follows a three-dimensional instantaneous nucleation model.

\section{Conclusions}

(1)The electrodeposition of $\mathrm{Zn}-\mathrm{Ni}$ alloy on copper foil with carrier is studied. Nickel and zinc are found to be co-deposited easily in a normal way in potassium pyrophosphate system as reflected from the cyclic voltammetry curves of nickel-zinc alloy. The deposition processes start with the deposition of 
nickel on carrier copper foil, followed by the co-deposition of zinc-nickel upon the reach of zinc deposition potential.

(2)The co-deposition process of zinc-nickel alloy is a quasi-reversible process controlled by diffusion in potassium pyrophosphate system as indicated from the cyclic voltammetry curves at different scanning speed.

(3)The chronoamperometry results show that the electrodeposition process of zinc-nickel alloy follows a three-dimensional instantaneous nucleation model.

\section{Acknowledgments.}

This study was financially supported by the National Natural Science Foundation of China (51104072).

\section{References}

[1] G Y Li , J S Lian , L Y Niu, et al., Surface \& Coatings Technology, 191 (2005), pp.59-67.(In Chinese)

[2] Wei Tian, Faqin Xie, Xiangqing Wu, Materials Protection, 41(1) (2008), pp.28-30.(In Chinese)

[3] Yingjie Zhang, Peng Dong, Yunying Fan, Materials Protection, 40(11) (2007), pp.45-48.(In Chinese)

[4] Liyuan Niu, Automobile Technology \& Material, 7 (1999), pp.12-15.(In Chinese)

[5] Brenner A, Electrodeposition of Alloys, Vol.II[M]. NewYork: Academic Press, (1963), pp.222.

[6] Gang Kong, Jintang Lu, Jinhong Chen, et al., Materials Protection, 32(6) (1999), pp. 6-7.(In Chinese)

[7] Peng Dong, Yingjie Zhang, Yunying Fan, Surface Technology, 36(3) (2007), pp.10-11.(In Chinese)

[8] Junhua Li, Daizhi Kuang, Yonglan Feng, Jingnian Qu, Rongying Zeng, Chemical Agent, 33(2) (2011), pp.152-156.(In Chinese)

[9] Yongfeng Jiang, Chunquan Zhai, Xingwu Guo, Wenjiang Ding, Journal of Materials Science \& Engineering, 21(4) (2003), pp.586-589.(In Chinese)

[10] Jingcheng Tian, Juan Miao, Dexue Fu, Journal of Zhongzhou University, 22(4) (2005), pp.112-114.(In Chinese)

[11] Jueqi Huang,Ganzhou: Jiangxi University of Science and Technology.(2012) .(In Chinese)

[12]M.Schwartz. N.V.Myung. K.Nobe, J.Electrochem.Soc., 151(7) (2004), pp.C468-C477.

[13]B.Schariflker, G. Hill, Electrochim Acta. 28(7)(1983), pp.879-889. 